\title{
Construction of fairways and reconstruction of channels using rotary-bucket dredgers and calculation of soil-collecting devices
}

\author{
Yurii Volodin ${ }^{1 *[0000-0002-7621-1520]}$, Olga Marfina ${ }^{1}$, Nikolay Arefyev ${ }^{2}$, Yurii Matveev², and \\ Nikolay Popov ${ }^{2}$ \\ ${ }^{1}$ Kazan State University of Architecture and Engineering, 420043 Kazan, Russia \\ ${ }^{2}$ Volga State University of Water Transport, 603950 N. Novgorod, Russia
}

\begin{abstract}
Rotary bucket dredgers are used in various operations: dredging, mining, development of all types of soil. Despite their high weight, cost and complexity of construction, they are increasingly used in underwater soil development due to their versatility and high efficiency. The article presents the developed method for calculating the rotary bucket dredgers, taking into account their placement under water.
\end{abstract}

Keywords. Construction of fairways and reconstruction of channels, dredgers, soil-collecting devices, rotary bucket rippers, dredging, underwater mining.

\section{Introduction}

The development of the transport system is an urgent issue for every country, especially for Russia, which has the largest territory in the world. The transport system in such a large country consists of all types of transport: air, rail, road, and water, including of sea and river fleets. There are many rivers in Russia, including navigable ones. Sometimes, due to weather and climate conditions or for other reasons, the water level in rivers decreases; this is a bad factor that interferes with navigation on rivers. Therefore, maintaining the ability of vessels to pass through rivers is an important technical and economic task. Dredgers are used for dredging operations. They can be dredged [1-5] and bucket [6-11]. Such machines are used not only in fulfilling the works on deepening the bottom, but also in the construction of channels [12-14], retaining walls and piers [15, 16], bridges [14] and other objects [2, 3, 17-19], as well as in the development of all types of soil and mining. Rotary bucket dredgers are used both for dredging [20-24] and for mining operations [6, 8, 14, 15, 23, 25]. It should be noted that rotary bucket dredgers are effective in the development of various types of soil, but are complex in design, have a large mass and high cost. However, due to their versatility, such machines are increasingly being used $[13-15,19,23,26]$. Therefore, there is a need to develop methods for calculating them. Some calculation methods are known, for example, for rotary bucket rippers used in rotary excavators [24-26]. In addition, it should be noted that it is necessary to take into account the heat losses in the pipelines of the bucket dredger

${ }^{*}$ Corresponding author: yu.g.volodin@mail.ru 
drive systems [27-29]. The method presented in the article for calculating the rotary bucket ripper as a part of the dredger's ground intake device is performed taking into account the known methods, as well as considering the process of their immersion under water.

\section{Materials and methods}

The dredger is a fairly complex technical structure, which includes the achievements of various branches of technology. One of the main elements of the dredger is a rotary bucket ripper, the scheme of which is shown in Fig. 1. The rotary bucket dredger includes a rotary bucket ripper 1 with buckets 2 and knives 3, a hydraulic drive 4, a suction pipe 5, a ground receiver 6 , mounted on a frame 7 . Let's perform the calculation of the rotary bucket ripper, for which.

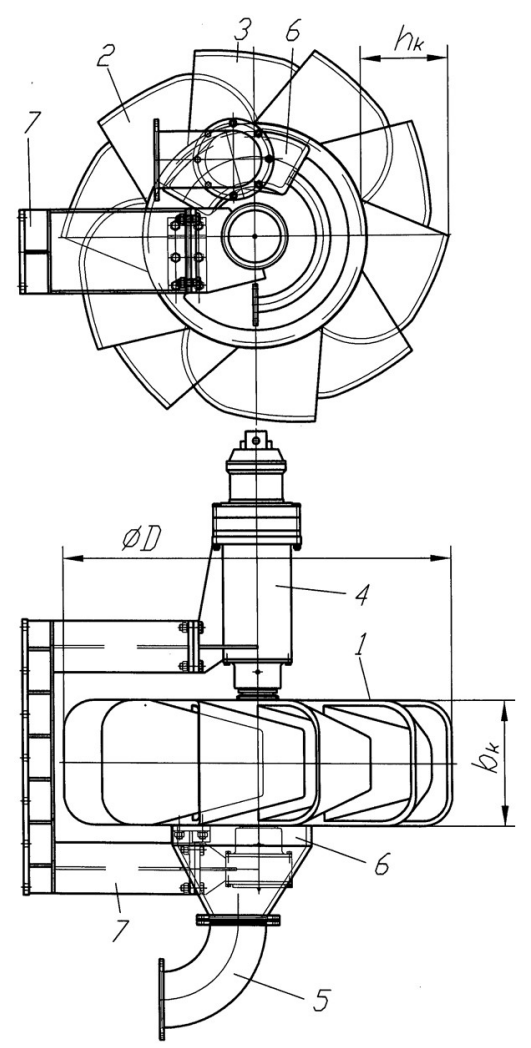

Fig. 1. Scheme of the rotary-bucket grunt intake the device of the dredger.

\subsection{Define its parameters}

According to the methods described in [24-26], we calculate the diameter $D$ of the rotary ripper taking into account the location under water by the formula, $\mathrm{m}$ :

where $Q_{\mathrm{gr}}-$ soil productivity, $\mathrm{m}^{3} / \mathrm{h}$.

$$
D=0.3 \cdot \sqrt[3]{Q_{\mathrm{gr}}}
$$

Determine the number of $z$ buckets on the rotor:

$$
z=4+0.08 \cdot \sqrt{Q_{\mathrm{gr}}}
$$


Taking into account the work [24], the number of $z$ is taken in the range 5-9. The critical rotation speed of the $n_{k r}$ under the conditions of gravitational unloading of the rotor under water is determined by the expression, turnovers/minute:

$$
n_{k r}=\frac{30}{\pi} \cdot \sqrt{\frac{2 g}{D}}\left(1-\frac{\rho_{\mathrm{B}}}{\rho_{\mathrm{gr}}}\right),
$$

where $\rho_{\theta}$ is the density of water, $\mathrm{kg} / \mathrm{m}^{3}, \rho_{g r}-$ soil density, $\mathrm{kg} / \mathrm{m}^{3}$. If we take $\rho_{g r}=2400 \mathrm{~kg} / \mathrm{m}^{3}$, then from (1.3) we get, turnovers/minute:

$$
n_{k r}=\frac{32.3}{\sqrt{D}}
$$

According to [24], the rotor spinning frequency $\mathrm{n}$ is assumed, turnovers/minute:

$$
n=(0.4 \div 0.6) \cdot n_{k r}
$$

The number of $n_{r}$ offloads is determined by the formula, $1 / \mathrm{min}$ :

$$
n_{r}=n \cdot z \text {. }
$$

Bucket capacity $q$ is calculated using [24], $\mathrm{m}^{3}$ :

$$
q=\frac{Q_{\mathrm{gr}} k_{r}}{60 \cdot k_{\mathrm{n}} \cdot z \cdot n}
$$

where $k_{r}$ - is the soil loosening coefficient; $k_{n}-$ is the bucket filling coefficient, $k_{n}=0.9 \div 1.2$. According to [25] we accept:

$k_{r}=1.3 \div 1.35$ - sand, sandy loam, light loam;

$k_{r}=1.5 \div 1.55$ - loam, heavy loam, clay;

$k_{r}=1.4 \div 1.45-$ shale clay, coal.

According to [25], the bucket departure $h_{k}$ is defined by the expression, m:

$$
h_{k}=\sqrt[3]{\frac{q}{k_{q}}},
$$

where $k_{q}=0.8$ - for cohesionless soils; $k_{q}=1$ - for medium-cohesive soils;

$k_{q}=1.25$ - for cohesive soils.

According to the recommendations in [25], we determine the width $b_{k}, \mathrm{~m}$ :

$$
b_{k} \geq h_{k} \text {. }
$$

\subsection{We calculate the velocity $V_{n}$ of papilionidae}

Speed $V_{n}$ of papilioninae is determined by the formula, $\mathrm{m} / \mathrm{min}$ :

$$
V_{n}=\frac{Q_{\mathrm{gr}}}{60 \cdot F_{p l}}
$$

where $F_{p l}-$ is the actual cross-sectional area of the papillonage tape, $\mathrm{m}^{2}$. The chip height $h_{c}$ and the maximum width $S_{\max }$ of the papillonage tape (Fig. 2) can be taken in accordance with the recommendations [25], $\mathrm{m}$ :

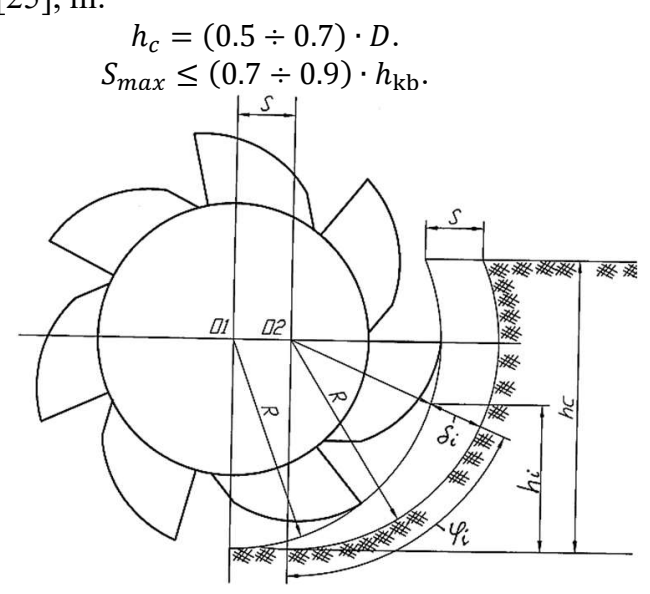

Fig. 2. Cutting scheme of the soil. 
Then the area $F_{p l}$ is defined by the expression, $\mathrm{m}^{2}$ :

$$
F_{p l}=h_{c} \cdot S,
$$

where $S-$ is the width of the papillonage tape, m. The minimum value of the speed $V_{n}^{\text {min }}$ of papillonation can be calculated for $S=S_{\max }$ by the expression, $\mathrm{m} / \mathrm{min}$ :

where it is accepted $h_{c}=0.7 D ; S_{\max }=0.9 h_{\kappa}$.

$$
V_{\Pi}^{\min } \geq \frac{Q_{\mathrm{gr}}}{37.8 \cdot D \cdot h_{\mathrm{K}}} \text {. }
$$

The width $b_{0}$ of the chip (Fig. 3) - the distance along the paper tape that the rotor passes in one revolution - is determined by the formula, $\mathrm{m}$ :

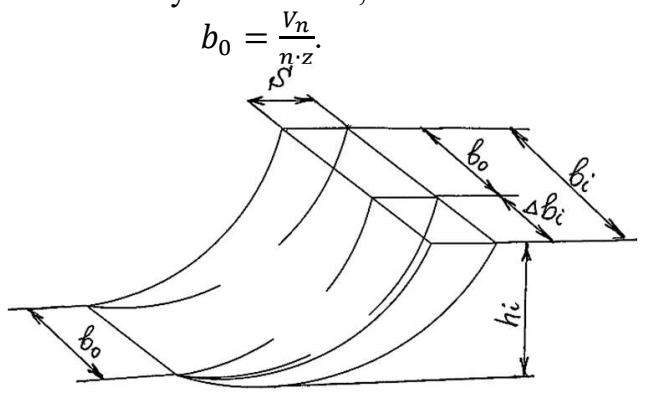

Fig. 3. The cross section of the chip.

The width $b_{0}$ of the chip should not exceed $0.9 b_{k}: b_{0}{ }^{\max } \leq 0.9 b_{k}$. With this in mind, from (2.6) we get the maximum value of the papillonage speed $V_{n}^{\max }, \mathrm{m} / \mathrm{min}$ :

$$
V_{\Pi}^{\min } \leq 0.9 b_{k} \cdot n \cdot z
$$

The movement $\Delta b_{i}$ of the bucket along the paper tape at the height of the chip $h_{i}$ is determined by the expression, $\mathrm{m}$ :

$$
\Delta b_{i}=\frac{V_{n} \cdot \varphi_{i}}{2 \pi \cdot n}
$$

Then, taking into account (2.6), we can write, $\mathrm{m}$ :

$$
b_{i}=\frac{V_{n}}{n}\left(\frac{1}{z}+\frac{\varphi_{i}}{2 \pi}\right) \text {. }
$$

In the calculations, we take $h_{i}^{\text {min }} \geq 0,25 h_{\kappa}$ and receive:

$$
\varphi_{i}^{\min }=\arccos \left(\frac{R-0.25 h_{k}}{R}\right) \text {, }
$$

where $R=D / 2$. Taking into account (2.5) and (2.10) for (2.9) $b_{i}{ }^{m i n}$ is determined.

\subsection{Calculation of cutting forces}

The cutting force can be represented as a tangent $P_{\tau}$, directed tangentially to the curve described by the scoop cutter, and normal to it $P_{N}$, which are determined taking into account the research [30], $\mathrm{kN}$ :

$$
\begin{gathered}
P_{\tau}=k_{4}^{I} \cdot f+k_{5}^{I} \cdot t \cdot l, \\
P_{N}=k_{5}^{I} \cdot t \cdot l \cdot \operatorname{ctg}\left(\gamma_{3}+\mu\right),
\end{gathered}
$$

where $k_{4}{ }^{I}, k_{5}{ }^{I}$ are the reduced ground shear and crumple resistances, respectively, $\mathrm{kPa}$;

$f$ - cross-section area of the ground chips to be cut, $\mathrm{m}^{2}$;

$t$ - thickness of the blunted cutting edge of the knife, m;

$l$ - length of the cutting edge of the scoop, $\mathrm{m}$;

$\gamma_{3}$ - the angle of inclination of the wear pad to the path of the cutting edge of the scoop (in calculations, you can take $\gamma_{3}=17 \div 25^{\circ}$ );

$\mu$ - the angle of external friction of the soil [31,32].

The values of $k_{4}{ }^{I}$ and $k_{5}{ }^{I}$ in accordance with the research $[31,32]$ are calculated using the expressions, $\mathrm{kPa}$ :

$$
k_{4}^{I}=k_{4} \cdot \frac{\cos \rho}{\cos ^{2}\left(\frac{\pi}{4}+\frac{\rho}{2}\right)},
$$




$$
k_{5}^{I}=k_{5} \cdot \frac{\sin \left(\gamma_{3}+\mu\right)}{\cos \mu}
$$

where $k_{4}$ and $k_{5}$ - are the specific resistances of the soil to shear and crumple, respectively, $\mathrm{kPa} ; \rho$ - the angle of internal friction of the soil. According to [31,32], the values of $k_{4}, k_{5}$, and $\rho$ are determined depending on the type of soil.

The cross-section area of the ground chips to be cut is equal to, $\mathrm{m}^{2}$ :

$$
f_{i}=\delta_{i} b_{i}
$$

where $\delta_{i}-$ is the thickness of the ground chip to be cut, m; $b_{i}$ - chip width, measured by the normal to the side surface of the cut, $\mathrm{m}$. The value of $\delta_{i}$ is defined, $\mathrm{m}$ :

$$
\delta_{i}=R+S \cdot \sin \varphi_{i}-\sqrt{R^{2}-S^{2} \cdot \cos ^{2} \varphi_{i}} .
$$

The $b_{i}$ value is found by (2.9). Substituting (2.9) and (3.6) in (3.5), we get, $\mathrm{m}^{2}$ :

$$
f_{i}=\frac{V_{n}}{n}\left(\frac{1}{z}+\frac{\varphi_{i}}{2 \pi}\right) \cdot\left(R+S \cdot \sin \varphi_{i}-\sqrt{R^{2}-S^{2} \cdot \cos ^{2} \varphi_{i}}\right)
$$

Taking into account [30] we accept, $\mathrm{m}$ :

$$
l_{i}=\delta_{i}+b_{i} \text {. }
$$

Substituting in (3.8) the expressions (2.9) and (3.6), we get, m:

$$
l_{i}=\frac{V_{n}}{n}\left(\frac{1}{z}+\frac{\varphi_{i}}{2 \pi}\right)+R+S \cdot \sin \varphi_{i}-\sqrt{R^{2}-S^{2} \cdot \cos ^{2} \varphi_{i}} .
$$

For $h_{i}=R$ we have $\varphi_{i}=\pi / 2$. Then, substituting this value in (3.7) and (3.9), we find:

$$
\begin{aligned}
& f_{90}=\frac{V_{n}}{n}\left(\frac{1}{z}+\frac{1}{4}\right) \cdot S, \\
& l_{90}=\frac{V_{n}}{n}\left(\frac{1}{z}+\frac{1}{4}\right)+S .
\end{aligned}
$$

Intermediate values of $\varphi_{i}$ can be defined by expressions:

- if $h_{i} \leq D / 2$, then:

- if $h_{i}>D / 2$, then:

$$
\varphi_{i}=\arccos \left(\frac{R-h_{i}}{R}\right)
$$

$$
\varphi_{i}=\frac{\pi}{2}+\arccos \left(\frac{h_{i}-R}{R}\right) .
$$

The angle $\alpha$ between the bucket cutters is calculated using the formula:

$$
\alpha=\frac{2 \pi}{z} \text {. }
$$

\subsection{Determine the drive power}

The total power $N_{r}$ of the rotor drive is found by the expression, $\mathrm{kW}$ :

$$
N_{r}=N_{\text {rez }}+N_{\text {pod }}+N_{\text {fr }}+N_{\text {zap }}+N_{\text {kin }}+N_{\text {hf }}
$$

where $N_{\text {rez }}-$ power to the cutting of soil, $\mathrm{kW}$;

$N_{\text {pod }}$ - power to the rise of ground, $\mathrm{kW}$;

$N_{\text {fr }}$ - power to overcome friction on the shut-off sector, $\mathrm{kW}$;

$N_{\text {zap }}$ - capacity for filling buckets with soil, $\mathrm{kW}$;

$N_{\text {kin }}$ - power per message to the soil that got into the bucket, kinetic energy, $\mathrm{kW}$;

$N_{\mathrm{hf}}$ - power to overcome hydraulic resistances when the buckets flow with water and when the rotor spins under water, $\mathrm{kW}$. Please note that $N_{t r}+N_{z a p}+N_{k i n}+N_{g . s}$ according to $[25,30]$ make up $2-5 \%$ of the power $N_{r e z}$. Therefore, they can be ignored in calculations. The rotor torque when cutting soil is determined by the formula, $\mathrm{kN} \mathrm{m}$ :

$$
M_{k r}=\left(\sum_{i=1}^{k} P_{v}\right) \cdot R
$$

where $k$ - is the number of cutters simultaneously involved in cutting the ground.

The cutting power of the soil is determined by the expression, $\mathrm{kW}$ :

$$
N_{r e z}=M_{k r} \cdot \omega=\frac{M_{k r} \cdot \pi \cdot n}{30} .
$$

After substituting (4.2) in the above expression, we get, $\mathrm{kW}$ :

$$
N_{r e z}=\frac{\left(\sum_{i=1}^{k} P_{v}\right) \cdot D \cdot \pi \cdot n}{60} .
$$


The power to lift the soil to the place of unloading the bucket, taking into account [25], is determined by the formula, $\mathrm{kW}$ :

$$
N_{\text {pod }}=\frac{Q_{\mathrm{gr}}}{4800} \cdot \rho_{\mathrm{gr}} \cdot g \cdot D
$$

where $\rho_{\mathrm{gr}}$ is the density of soil, $\mathrm{kg} / \mathrm{m}^{3} ; \mathrm{g}=9.81 \mathrm{~m} / \mathrm{s}^{2}$ - acceleration of free fall. The power of the rotor drive is calculated by (4.1) taking into account (4.3) and (4.4), $\mathrm{kW}$ :

$$
N_{r}=1.05 \frac{\left(\sum_{i=1}^{k} P_{v} \cdot D \cdot \pi \cdot n\right.}{60 \cdot \eta_{r}}+\frac{Q_{\mathrm{gr}} \cdot \rho_{\mathrm{gr}} \cdot g \cdot D}{4800 \cdot \eta_{r}},
$$

where $\eta_{r}$ - efficiency of the rotor takes into account the friction losses in the suspension bearings (in calculations, you can take $\eta_{r}=0.75 \div 0.85$ ).

\subsection{Determine the forces acting on the rotor}

The horizontal force of the $P_{g d}$ acting on the rotor along the diameter plane of the dredger is determined by the expression, $\mathrm{kN}$ :

$$
P_{g d}=\sum_{i=1}^{k}\left(P_{v} \cdot \cos \varphi_{i}\right)+\sum_{i=1}^{k}\left(P_{N i} \cdot \sin \varphi_{i}\right) .
$$

The horizontal force $P_{g N}$ acting on the rotor perpendicular to the diameter plane of the dredger is calculated by the formula, $\mathrm{kN}$ :

Vertical force $P_{h}$ acting on the rotor, $\mathrm{kN}$ :

$$
P_{g N}=k_{5}^{I} \cdot t \cdot \operatorname{ctg}\left(\gamma_{3}+\mu\right) \cdot \sum_{i=1}^{k} \delta_{i} \text {. }
$$

$$
P_{h}=\sum_{i=1}^{k}\left(P_{v} \cdot \sin \varphi_{i}\right)-\sum_{i=1}^{k}\left(P_{N i} \cdot \cos \varphi_{i}\right) \text {. }
$$

The values of $P_{\tau i}$ and $P_{N i}$ are determined by (3.1) and (3.2) depending on the position of the cutting blades of the rotor buckets that are engaged with the ground.

\section{Results and discussions}

The calculation of the technical and economic indicators of the operation of the rotor-bucket dredger as a function of the rotational speed $n$ of the shaft is carried out.

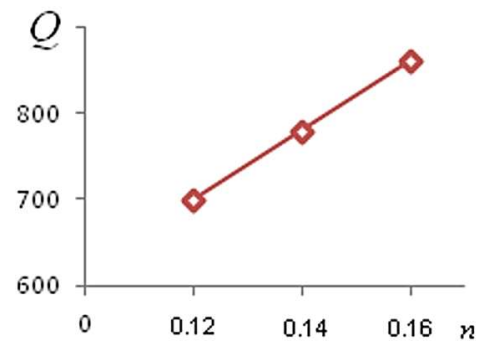

a)

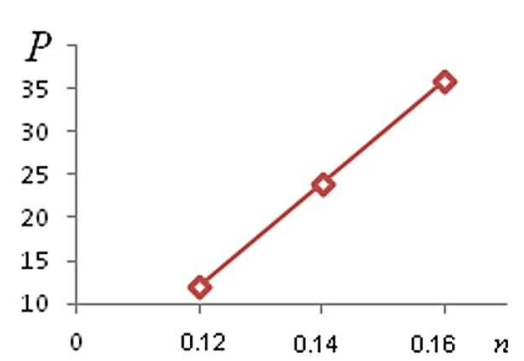

b)

Fig. 4. Graphs of the dependence of a) performance $Q$ and b) power $P$ on the speed $n$.

Fig. 4 shows two graphs. Both dependences $Q(n)$ and $P(n)$ are linear. From the graphic it can be seen that an increase in the rotational speed $n$ of the shaft allows increasing the productivity $Q$ of the machine to a maximum value. The limitation of the increase in productivity $Q$ is the power consumption $P$ of the machine and the category of soil. In addition, the obtained dependencies allow, in specific conditions, to obtain the optimal values of technical and economic indicators for the corresponding rotational speed $n$ of the shaft.

\section{Conclusion}

The proposed method for calculating a rotor-bucket dredger is an important and necessary methodological basis both when optimizing the values of the technical and economic 
indicators of the dredger performance during its operation, and when performing design work during the development of new types of equipment (dredgers, excavators, etc.), used in the fulfilling of various works: dredging, mining, development of all types of soil under water. Despite their significant massiveness, high cost and design complexity, they are increasingly used in underwater excavation due to their versatility and high efficiency.

The developed calculation method was applied in the design of a rotary bucket dredger with a ground pump with a water-ground mixture of $800 \mathrm{~m}^{3} / \mathrm{h}$ in JSC «Tsimlyansky shipmechanical plant».

\section{References}

1. Z. Bai, X. Hu, B. Wang, Z. Hu, X. Yang, T. Zhao. Optimization of shaft-seal water system of cutter suction dredger based on high-efficiency centrifugal separation technology, Separation and Purification Technology 236, (2020).

2. J. Litwin. Vistulian dredgers and their boats (19-20 th century), Biuletynu Polskiej Misji Historycznej 14, 225-250 (2019).

3. J. Hu, L. Gao, S. Fan, Y. Si, E. Liu. The Modeling and Simulation Research on the Electric Drive System of Cutter Suction Dredger, Journal of Wuhan University of Technology (Transportation Science and Engineering) 41 (5), 875-880 (2017).

4. S. Mohapatra, A. Shaikh, P. Nayak, R. Navada. Hazards and health risks encountered by manual sand dredgers from Udupi, India: A cross-sectional study, Journal of Clinical and Diagnostic Research 11 (7), LC11-LC17 (2017).

5. P. Yao, Z. Chen, J. Tong, L. Qian. Virtual simulation system of cutter suction dredger based on Unity3D, Journal of System Simulation 28 (9), 2069-2075 (2016).

6. P. Poullet, J.J. Muñoz-Perez, P. Lopez, S. García-Lopez, R. Martell, R. Silva, L. Moreno. Sand size variability inside the hopper of a trailing suction dredger for beach nourishment purposes, Geo-Marine Letters 39 (6), 513-520 (2019).

7. X. Wang, Y. Weng, H. Wei, Q. Meng, M. Hu. Particle obstruction and crushing of dredged calcareous soil in the Nansha Islands, South China Sea, Engineering Geology 261, (2019).

8. F. Zhuang, J. Zhang, Y. Hao, X. Mao, Y. Zhang. Study on sediment diffusion in nostorage-pit dredging operation, Journal of Hydroelectric Engineering 38 (10), 111-120 (2019).

9. D.H. Grover. Vessel for offshore sand and gravel mining proposed. World dredging \& amp, Mar. Constr. 21, 18-19. (2017).

10. H.L. Wakeling, N.J. Cox, S. Ghosh, B.A. O'Connor. A study of littoral drift at Paradip, India, Proc. Int. Conf. on coastal and port engineering in developing countries, Sri Lanka, Conventions (Colombo) Ltd., 1192-1206 (2017).

11. R. de Leeuw. Foundation bed preparation, Dredging \& amp; Port constr. (Supplement) 13, 17-19 (2017).

12. K. Miyamoto, A. Ito. A study of a bucket pin. World dredging \& amp; Mar. Constr. 17, 19-23 (2017).

13. R. Fleming. Five dredgers in record harness for final St Philipsdam closure, Dredging \& amp; Port Constr. 14, 19-21 (2017).

14. X.-M. Chen, Z.-R. Zeng. Techniques for Emergency Repairing and Strengthening of Zhaoqing Xijiang River Bridge Collided by Sand Dredger, Bridge Construction 47 (2), 100-105 (2017).

15. J. Wang, Y. Deng, Y. Shao, X. Liu, B. Feng, L. Wu, J. Zhou, Y. Yin, N. Xu, H. Peng. Liquefaction behavior of dredged silty-fine sands under cyclic loading for land reclamation: laboratory experiment and numerical simulation, Environmental Earth Sciences 77 (12), (2018). 
16. Y.-T. Chen, G.-J. Wang, F.-Q. Meng, Y. Xu. Application and analysis of the geotextile composite cushion in the ground improvement of the new dredger fill, Chinese Journal of Geotechnical Engineering 38, 169-172 (2016).

17. C.-Y. Zhang, M. Chen, M.-J. Hu, X.-Z. Wang, J.-J. Tang. Effect of fine particles content on shear strength of calcareous sand, Rock and Soil Mechanics 40, 195-202 (2019).

18. P. Wang, X. Zhang, S. Qi. Was the trend of the net sediment flux in Poyang Lake, China, altered by the Three Gorges Dam or by sand mining? Environmental Earth Sciences 78 (3), (2019).

19. J. Ding. Application Research of Straight-line Vacuum Preloading Method in Dredger Fill Area, Journal of Railway Engineering Society 36 (1), 21-25 (2019).

20. H. Bokuniewicz, S.G. Jang. Dredging Intensity: A Spatio-Temporal Indicator for Managing Marine Resources, Environmental Management 62 (5), 987-994 (2018).

21. J. Liu, H. Lei, G. Zheng, H. Zhou, X. Zhang. Laboratory model study of newly deposited dredger fills using improved multiple-vacuum preloading technique, Journal of Rock Mechanics and Geotechnical Engineering 9 (5), 924-935 (2017).

22. B.Yu. Sobko, O.V. Lozhnikov, A.M. Haidin, O.M. Laznikov. Substantiation of rationalmi ning method at the Motronivskyi Titanium-Zirconium ore deposit exploration, Naukovyi Visnyk Natsionalnoho Hirnychoho Universytetu 6, 41-48 (2016).

23. IHC wheel dredgers for canal project in the Middle East. Ports \& amp; Dredging 119, 18-22. (2017).

24. Excavation machines. Under the general editorship of D.P. Volkova. M.: Mechanical engineering, 448 (1992).

25. Yu.I. Belyakov, V.M. Vladimirov. Working bodies of bucket wheel excavators. M.: Mechanical engineering, 179 (1967).

26. N.G. Dombrovsky. Multi-bucket excavators: design, theory and calculation. M.: Mechanical engineering, 432 (1972).

27. Y. Volodin, O. Marfina, M. Tsvetkovich. The study of gas flow in the industrial smoke pipe, Journal IOP Conf. Series: Materials Science and Engineering 890, 012160 (2020).

28. G. Marchenko, Y. Volodin, O. Marfina. Optimization of the profile of axisymmetric components of nozzles, Journal Welding International 26 (2), 148-151 (2012).

29. G. Akhmerova, A. Zalyalova, R. Mukhametshina. Impact of soil moisture on heat losses of pipelines of district heat supply networks at underground channel - free gasket, Journal Conf. Series: Materials Science and Engineering 890, 012153 (2020).

30. N.N. Arefyev. The movement of silty soils in the channels of the auger dredgers of suction dredgers. N. Novgorod: Publishing house of VGUVT, 146 (2017).

31. V.A. Ivanov, N.V. Lukin, S.N. Razzhivin. Technical fleet vessels. M.: Transport, 366 (1982).

32. S.P. Ogorodnikov. Hydromechanization of soil development. M.: Stroyizdat, 255 (1986). 